the electromagnetic waves in wireless transmission. It is a purely formal matter to say that these waves consist of photons, since the conditions under which we control the emission and the reception of the radio waves preclude the possibility of determining the number of photons they should contain. In such a case we may say that all trace of the photon idea, which is essentially one of enumeration of elementary processes, has completely disappeared.

For the sake of illustration, let us imagine for a moment that the recent experimental discoveries of electron diffraction and photonic effects, which fall in so well with the quantum mechanical symbolism, were made before the work of Faraday and Maxwell. Of course, such a situation is unthinkable, since the interpretation of the experiments in question is essentially based on the concepts created by this work. But let us, nevertheless, take such a fanciful view and ask ourselves what the state of science would then be. I think it is not too much to say that we should be farther away from a consistent view of the properties of matter and light than Newton and Huygens were. We must, in fact, realise that the unambiguous interpretation of any measurement must be essentially framed in terms of the classical physical theories, and we may say that in this sense the language of Newton and Maxwell will remain the language of physicists for all time.

I do not think that this is a proper occasion to enter into further details regarding these problems, and to bring new views under discussion. In conclusion, however, I am glad to give expression to the great expectation with which the whole scientific world follows the exploration of an entirely new field of experimental physics, namely, the internal constitution of the nucleus, which is now carried on in Maxwell's laboratory, under the great leadership of the present Cavendish professor. In the fact that nobody here in Cambridge is likely to forget Newton's and Maxwell's work, we see perhaps the very best auguries for the continued success of these endeavours. Even if we must be prepared for a still further renunciation of ordinary visualisation, the basic concepts of physics which we owe to the great masters will certainly prove indispensable in this new field as well.

\title{
The Temples of Yucatan: Work of the Scientific Restorer.
}

AL the great eastward-jutting promontory of A Yucatan and Quintana Roo is covered with the ruins of stone temples, erected by architects of great skill, and often beautifully decorated with carvings and wall paintings. Lying between the Usumacinta River and the Caribbean, the region is a low tableland of limestone, scarcely raised from the sea, its general flatness relieved only by a few hills two or three hundred feet high ; no rivers run in all the promontory, the abundant rain falling between May and December soaking through the thin layer of soil-frequently no more than a few inches deep-to the natural limestone hollows that serve Yucatan as wells. Sub-tropical, genial, extremely productive where any soil exists, the country's wild covering is light woodland, with peculiar and beautiful vegetation, sheltering hosts of birds and beasts.

This is the background of one of the great puzzles of the history of mankind. For while the evidence is rich, and almost endless, of the high accomplishments of a brilliantly artistic people, the early origins of these people, the reason of their coming to Yucatan, and the causes for the abandonment of site after site, are still mysterious. The most plausible suggestions are no more than guesses, and none is even reasonably adequate to explain the undoubted fact that the builders of many a splendid complex of pyramids and temples appeared in the region, set to work to cut-with stone tools, for these superb architects and masons did not know the use of metal-huge masses of stone ; to transport these masses, by man-labour, since they never had the help of the wheel; to set up and carve and paint great buildings ; to house and worship their gods, and to practise their astronomical skill; and that after sometimes no more than a hundred years or so, priests and builders marched away, leaving the stately buildings to become the haunt of wild creatures, to be overgrown with trees and forgotten.

According to the calculations of modern archæologists, the erection by the Maya of stone temples (probably preceded by structures of less enduring materials, such as wood and thatch) began before the Christian era ; and certain temples in Yucatan were still in occupation, as great religious and civic centres, in the early part of the sixteenth century, when the first Spaniards arrived. From the time of the Spanish conquest, the Maya and their culture suffered eclipse. A sponge was passed over the long record of their scientific and artistic attainments. With a few exceptions, to which students of American archæology owe a debt, the Spanish conquerors felt no curiosity concerning the ideas and civilisation of the vanquished people of Yucatan. They were heathen, their gods were idols; and the great pyramids merely served, when their uplifted temples were despoiled, as quarries for building material and sites for Christian churches.

The clan of learned men, priest-kings, adepts in astronomy, disappeared. They were not only the political leaders, but also the repositories of historical knowledge, experts in the art of recording. The Maya, alone among native American races, possessed a writing method, developed into an accurate system, concerned with historical and calendrical records. These records were carved in stone, and sometimes in wood, engraved in pottery, and painted upon parchment and upon paper made from the leaf of the maguey plant. The latter, collected sedulously by the Spanish missionaries, were burnt in heaps in the market-

No. 3234, VoL. 128] 
place of Merida; so careful was the search for these pagan documents that to-day only three Maya manuscripts are known to survive. The art of writing, and of reading the manuscripts and glyphs carved in stone, was irretrievably lostalthough, by the irony of fate, archæologists of to-day have puzzled out the meaning of about onethird of the writing by the aid of notes made by a Bishop of Yucatan, and by that aid alone.

Broadly, it may be said that for three hundred years, between the time of the Spanish conquest and the overthrow of the authority of Ferdinand VII., Maya culture was not only crushed in its development, but also ignored. The great series of temples, extending from Copan in the present Republic of Honduras, through Guatemala, through British Honduras, and spreading all over the Yucatec promontory, remained lost in the silence of the sub-tropical woodland; trees grew in the temples and disintegrated the great stone stairways. Maya speech survived; the humble folk, conforming to Spanish ways near towns, nevertheless retained customs and a large proportion of racial purity, especially in outlying regions; and, underneath and side by side with the Christianity patiently taught by missionary priests of Spain, maintained the cult of the ancient Maya gods.

Independence in Spanish America meant the collapse of a fence guarded for three centuries, and travellers came from all parts of the world, and particularly from Europe, to visit the regions formerly forbidden. By the middle of the nineteenth century a few inquisitive and enthusiastic travellers had seen some of the Maya ruins of Central America and Yucatan, and their books had startled a world which up to then regarded Greece and Rome as the chief fountains of romantic antiquity. Most things archæological were measured by these or the Egyptian standard. Even to-day, when ethnology has become a recognised science, it is not always possible to induce the neophyte to consider early American culture as something indigenous, basic, springing from the soil of the New World. If he cannot read Asia into American art, he must have Atlantis as a link.

Nevertheless, John Lloyd Stephens' "Incidents of Travel in Central America and Yucatan" became in the eighteen-forties a 'best-seller'; the drawings of Catherwood, illustrating the genial pen of the author, render this a perennially delight. ful travel book. The names of the splendid ruins of Copán and Quiriguá, Palenque and Uxmal, became familiar to the English-speaking world. Nothing, however, was done at the time to restore the ruins, or to make scientific examinations ; and the work of Maudslay, thirty years later, stands out as the first sustained effort to survey and record certain great sites.

The science of archæology, in fact, was only gradually attaining its stature. The serious worker in the field during the early years was hampered by heary expenses as well as physical difficulties. The example of Lord Elgin in Greece and of Lord Carnarvon in Egypt was not for some time followed in the Americas by any investigator after Maudslay; but when public interest became extended to-for example-Crete, and Ur of the Chaldees, the time was ripe for enterprise, already engaged in the Old World, to be directed to the untilled fields of the New.

A great step forward was made when the Carnegie Institution of Washington obtained in 1923, from the Government of Mexico, a concession to work

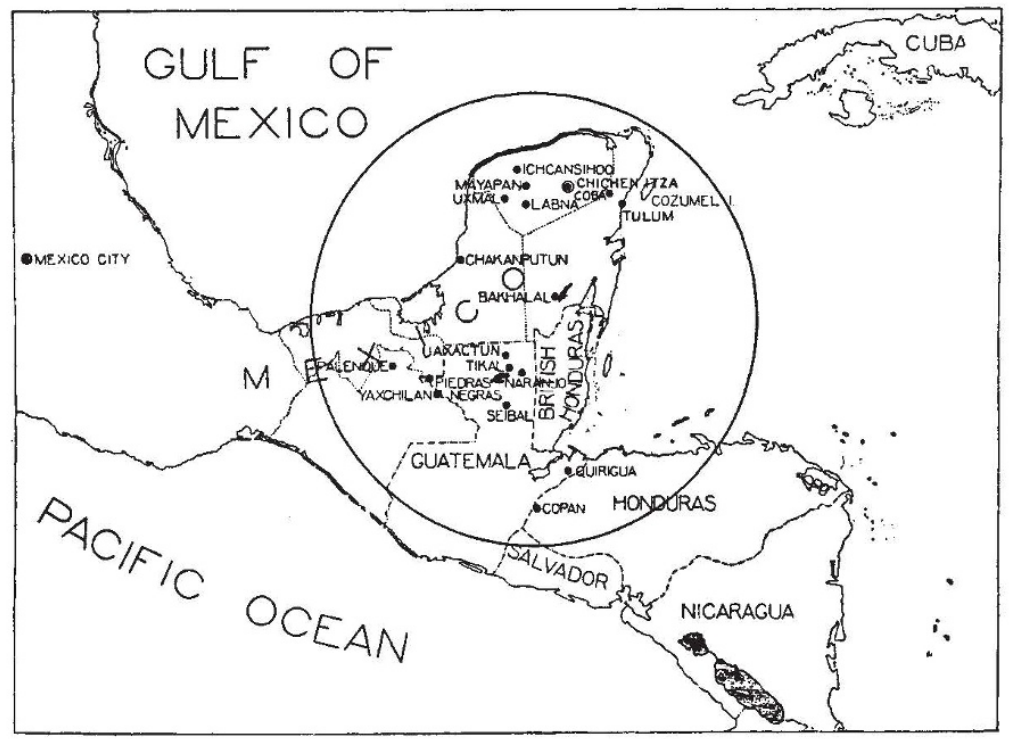

FIG. 1.-Maya region of Middle America.

rom "The Temple of the Warriors at Chichen Itzá, Yucatan".

No. 3234, VoL. 128]

for ten years in the magnificent complex cf ruins at Chichen Itzá in Yucatan (see Fig. 1).

Work was commenced in 1925, after careful preparations for many branches of scientific study to be followed, as well as for the physical work of clearing and restoration of certain ruins. For the Carnegie Institution, well supplied with funds, studies biology and linguistics side by side with archæological work; scientific surveys and photography are the work of special departments, and the labour of restoring Maya architecture is performed only after careful study. Every tool, thus, is put into the hands of the staff; the Institution has organised one of the best-equipped enterprises that has ever had the good fortune to work in the fascinating field of archæology, east or west.

Not least of the Carnegie Institution's merits is the broad line upon which the department dealing with publications is operated. In all branches of the widely distributed activities of the body, care is taken to make, preserve, and issue records of progress, generously presented to other workers 
in similar fields, throughout the world. To this department of publications is due a recently issued book invaluable to Americanists, produced in two

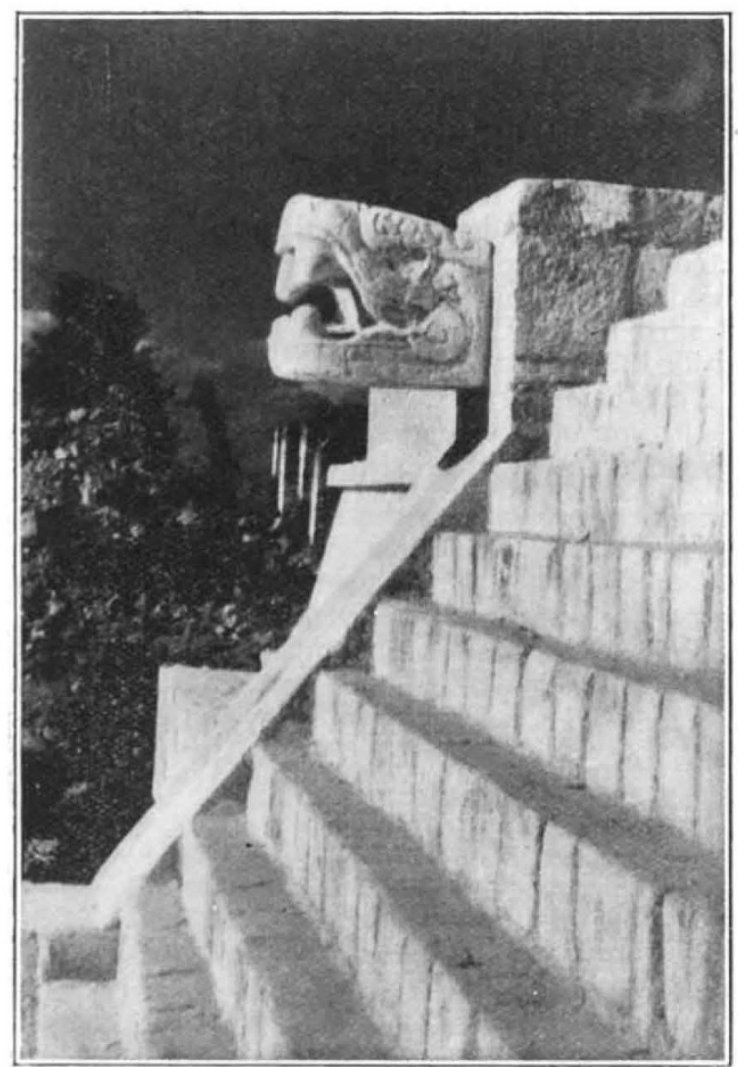

FiG. 2.--Serpent head at the top of north ramp of Warrior's Stairway. Columns of sanctuary of Temple of the Tables in the distance. From "The Temple of the Warriors at Chichen Itzá, Yucatan".

volumes, dealing with the field work of the Carnegie Institution at the great complex at Chichen Itzá known as the 'Temple of the Warriors'. * The pages measure some 12 in. by 9 in., the first volume containing 485 pages of text and illustrations, while the second consists of plates, of which many are printed in colour. Three persons are responsible for this magnificent record, Earl H. Morris, M. Jean Charlot, and Ann Axtell Morris, and the colleagues are to be congratulated upon work shedding light upon an extraordinary period in the history of Yucatan. When the staff of the Chichen Itzá project began work in January 1925, the slopes of the Temple of the Warriors were densely clothed with bushes, a few axe-cut stumps showing that partial clearing had once been performed. "Presumably, this work was done by Maudslay in 1888. In thirty-seven years the forest would have had ample time to reach this stage of maturity," says Mr. Morris. Dilapidated stone carvings lay on the summit, the stairways were broken, and masses of debris were tangled with vegetation.

* Carnegie Institution of Washington. Publication No. 406 . * Carnegie Institution of Washington. Publication No. 406 :
The Temple of the Warriors at Chichen Itzá, Yucatan. By Earl
H. Morris, Jean Charlot, Ann Axtell Morris. Vol. 1. Pp. xix +485. Vol. 2. Pp. viii +170 plates. (Washington, D.C.: Carnegie Institu-

No. 3234, VoL. 128]
The original design of the great eomplex of buildings could scarcely be perceived. To-day, as those fortunate enough to have seen Chichen Itzá lately can say, the whole series of majestic buildings, with fantastic and vivid sculptures in the round, striking reliefs, and mural decorations, stand clear from the surrounding bush. The plan of the series is complicated. From the top of the great main stairway one looks down upon acres of colonnades, while all about the white tops of other pyramids and temples rise from shrubby background under a brilliant blue sky, some still in ruin and others undergoing restoration or completed; the fine pyramid of the Castillo, for example, owes its present dignity to the work of Mexican archæologists commissioned by the Federal Government of Mexico.

Research, skill, and unlimited patience have made the restoration of the Temple of the Warriors an act of grace. One fears the hand of the restorer, but Chichen has been fortunate; there has been no over-restoration; scrupulous care has been taken to follow ancient lines; and the result is not only satisfying to the eye but also convincing.

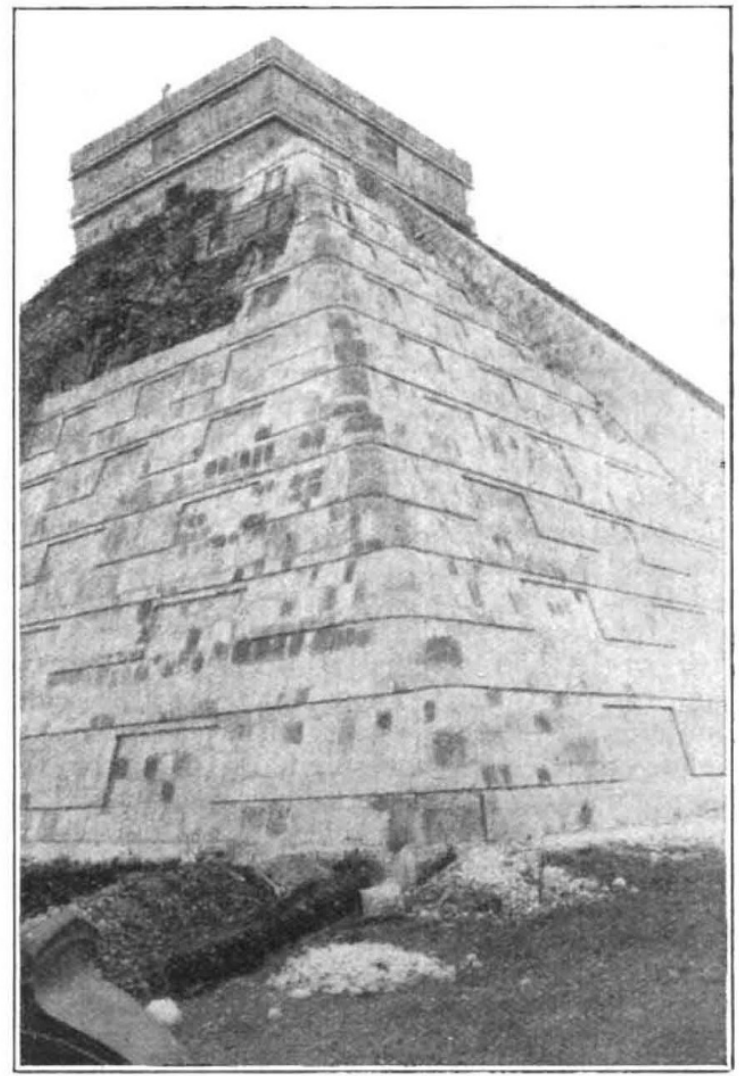

FIG. 3.-North-west corner of Castillo as repaired by Mexiean Government. Panelled effect of zones of pyramid is same as finish of sub-
structure of Temple of the Chac Mool. From "The Temple of the Warriors at Chichen Itzá, Yucatan",

The huge serpent columns, the Chac Mool figure, the atlantean altar, the mask panels of the façade, the sculptured bands that run along certain exterior walls, are beautiful examples of Maya art; 
but no less interesting are the evidences of the Maya architect's methods of construction. Stairways and vaulted chambers, columns and platforms, and enormous substructures are eloquent of the skill of these vanished people.

The Chichen Itzá project of the Carnegie Institution had devoted four field seasons of some four and a half months each to work on the Warriors when the present volume was written. Work has been under the direction of Dr. Sylvanus G. Morley throughout, who not only planned but also directed operations at Chichen. During the last twenty years, he has devoted himself to the Maya problem, and valuable results have been exemplified in his publications, as well as in the standing monument of the field work in Yucatan.

Few regions equal this strange promontory of the New World in opportunity for archæological investigation. The surface has only been scratched. Individuals and institutions able to share in the unravelling of problems in Yucatan, a chapter of the history of mankind, are to be envied.

\section{Obituary.}

Prof. Percy Groom, M.B.E., F.R.S.

$\mathrm{T}$ HROUGH the death of Prof. Percy Groom, which occurred at Gerrard's Cross on Sept. 16, there has passed away a man with an outlook and interests somewhat exceptional in the senior ranks of British botanists. He was born on Sept. 12, 1865, and entered Mason College, Birmingham, as a student, from which he passed to Cambridge on being elected to an exhibition at Trinity College. He obtained a first class in Part I. and a second in Part II. of the Tripos in 1887, taking botany as his principal subject. Afterwards he was elected to a Frank Smart studentship in botany at Caius College.

During his student life Groom studied for a time at the University of Bonn, where he enjoyed the friendship of the botanists, headed by the eminent Prof. Strasburger, who were making that university the Mecca of so many of the English-speaking followers of the science. He owed much to A. F. W. Schimper, and a delightful appreciation of that gifted man appears as a foreword to the translation of Schimper's "Plant Geography", revised by Bayley Balfour and himself, which was published by the Clarendon Press in 1903 . In 1889 he was appointed to the professorship of botany and arboriculture at the Imperial College of Whampoa, in China, and it was doubtless largely owing to this that he was led to turn his attention to the study of trees, and thence to their diseases and economic products, on which he largely concentrated his attention in after years.

On returning to England in 1892, Groom settled for some years in Oxford, migrating to Edinburgh in 1898 to take charge of the classes in plantphysiology under Prof. Bayley Balfour. His stay there was short, as he was appointed in the following year to the headship of the biological department in the Royal Indian Engineering College at Coopers Hill, in succession to Marshall Ward, and on the closing down of that College he came to London as head of the department of botany at the Northern Polytechnic. In 1908 he joined the staff at the Imperial College of Science and Technology, first as an assistant professor, and was promoted to the chair of the technology of woods and fibres in 1911, an appointment he held to the end of his life.

Groom was the author of several books, and he contributed a number of papers, mainly on the anatomy of flowering plants, to various scientific journals, but as time went on he became more and more identified with the 'applied side' of his subject, publishing many papers in various technical journals on timber and forestry topics, as well as on the various diseases which affect wood under the numerous and diverse conditions under which it is employed. He served as a member of many committees concerned with these various matters, and his assistance was often sought by those engaged in industry, as well as by various government departments. One of his last papers was written for the Public Record Office, entitled "A Preliminary Investigation on the Mildew of Book-covers in Relation to Humidity and Temperature of the Air ", and this investigation was still going on when he died. His work was recognised by his election to the fellowship of the Royal Society in 1924.

Groom's lectures at the Imperial College, especially those on timber for engineers and others interested in the technical side of the subject, were valued and were well attended. His place will not easily be filled, and as a colleague he will be held in affectionate remembrance by all who knew him.

J. B. F.

\section{Sir William Simpson, C.M.G.}

By the death of Sir William Simpson on Sept. 20 , after a few days' illness, a great exponent of tropical hygiene has passed away. William John Ritchie Simpson was born in Aberdeen, in 1855, where, after schooling in Jersey, he became a medical student, qualifying in 1876 and taking the M.D. degree four years later. He determined to choose public health as a career, and soon became the first medical officer of health of his native city and lecturer on hygiene in the University.

These posts were relinquished in 1886, when Simpson was appointed chief health officer in Calcutta, a position he held for twelve years, and thenceforward his life was devoted to the advancement of tropical hygiene and medicine. Returning to England, Simpson was elected, in 1898, professor of hygiene in King's College, London, and in 1899 was associated with the late Sir Patrick Manson and others in the foundation of the London School of Tropical Medicine, of which he became one of the lecturers.

From now onwards Simpson was almost conNo. 3234, VoL. 128] 